\title{
Macrophages participate in host protection and the disease pathology associated with Leishmania braziliensis infection
}

\author{
Angela Giudice ${ }^{1}$, Célia Vendrame', Caroline Bezerra', Lucas P Carvalho1, Thaís Delavechia', Edgar M Carvalho ${ }^{1,2}$ \\ and Olívia Bacellar ${ }^{1,2,3^{*}}$
}

\begin{abstract}
Background: Leishmania preferentially infects macrophages, which allow the parasite to multiply but can also kill the parasite. Although the T cell response in human leishmaniasis is well-characterized, little is known about the concomitant macrophage behavior. The aim of this study was to characterize the macrophage immune response after Leishmania braziliensis infection in cells derived from cutaneous leishmaniasis (CL) or mucosal leishmaniasis (ML) patients, subclinical individuals (SC) and healthy control subjects (HS).
\end{abstract}

Methods: Peripheral blood mononuclear cell-derived macrophages from the different groups were exposed to $L$. braziliensis in vitro and were evaluated for susceptibility to Leishmania infection, ability to kill Leishmania and chemokine/cytokine production. Nitric Oxide (NO) and superoxide $\left(\mathrm{O}_{2}{ }^{-}\right)$levels in the supernatant of infected macrophage cultures were monitored.

Results: After exposure to L. braziliensis, peripheral blood mononuclear cell-derived macrophages from SC individuals showed a lower infection rate and a smaller number of intracellular amastigotes compared to cells from $\mathrm{CL}$ and ML patients. Macrophages from $\mathrm{CL}$ and ML patients produced more chemokines and TNF- $\alpha$ than those from the SC group. Production of $\mathrm{NO}$ and $\mathrm{O}_{2}{ }^{-}$were detected but did not vary significantly among the different groups.

Conclusions: Our data indicate that macrophages play a pivotal role in controlling L. braziliensis infection and in leishmaniasis pathology by secreting pro-inflammatory chemokines/cytokines that activate and recruit $T$ cells, overwhelming the inflammatory response.

Keywords: L. braziliensis, Macrophages, Chemokines, Subclinical infection

\section{Background}

Leishmania Viannia braziliensis is the primary cause of American Tegumentary Leishmaniasis (ATL) in Brazil. Cutaneous leishmaniasis (CL), the most common form of ATL, is characterized by the appearance of a single or a few ulcerated skin lesions. A fraction (3\%) of CL patients develops mucosal disease, characterized by disfiguring lesions that usually involve the nasal or oropharyngeal mucosa [1,2]. CL and ML lesion biopsies show an intense inflammatory reaction, characterized by a predominance

\footnotetext{
* Correspondence: olivinhaufba@gmail.com

'Serviço de Imunologia, Complexo Hospitalar Universitário Professor Edgard Santos, Universidade Federal da Bahia, Salvador, Bahia, Brazil Full list of author information is available at the end of the article
}

of lymphocytes and macrophages and few or no detectable parasites [1]. In areas of endemic Leishmania transmission, approximately $10 \%$ of individuals have a positive Montenegro skin test (MST) but lack disease pathology [3-6]. These individuals are classified as subclinical (SC) or asymptomatic infection cases. The immunological response in CL and ML has been well-characterized. The type-1 immune response predominates in CL and ML, with an exaggerated production of IFN- $\gamma$ and TNF- $\alpha$ that fails to be modulated either by IL- 10 or TGF $\beta$ or by neutralizing antibodies to IL-12 and IL-15 [7,8]. Lymphocytes from ML patients proliferate more than those from CL patients when stimulated with parasite antigens and produce higher levels of IFN- $\gamma$ and TNF- $\alpha[7,9]$. This
C Biomed Central 
exacerbated type- 1 immune response is unable to control the disease and contributes to pathological tissue damage. In contrast, SC patients produce only low levels of IFN- $\gamma$ and TNF- $\alpha$ [10].

Macrophages, the host cells for the intracellular parasite Leishmania, are crucial for the outcome of disease. However, very little is known about macrophage behavior in human Leishmania infection. In addition to presenting antigens to $\mathrm{T}$ cells, macrophages secret chemokines and cytokines involved in the inflammatory response, such as IL-1 $\beta$ and TNF- $\alpha$ in response to Leishmania infection. Lesions from CL patients show increased expression of CCL2, CXCL9 and CXCL10 [11]. CCL2 and CCL3 are known to increase the leishmanicidal ability of human macrophages to the same level induced by IFN- $\gamma$ [12]. However, molecules such CXCL9, CXCL10 and TNF- $\alpha$, which are highly expressed in the tissue from $\mathrm{CL}$ and $\mathrm{ML}$ patients, participate in the inflammatory reaction that may lead to the tissue damage observed in CL and ML $[11,13]$.

When Leishmania parasites enter host macrophages, an oxidative burst occurs that is characterized by an increase in reactive oxygen species and reactive nitrogen intermediates, such as nitric oxide (NO). The mechanisms used by human macrophages to kill Leishmania are not yet well established. While NO production plays a role in killing Leishmania in mice, its role in humans is still questionable [14-16].

The aim of the present study was to characterize the immune response of macrophages from $\mathrm{CL}, \mathrm{ML}$, and SC patients and from healthy subjects (HS) after exposure to Leishmania. We evaluated the susceptibility of macrophages to infection by L. braziliensis and the ability of these cells to kill Leishmania. Additionally, we investigated the role of $\mathrm{NO}$ and $\mathrm{O}_{2}{ }^{-}$in killing the L. braziliensis parasite. We also evaluated the production of chemokines (CCL2, CCL3, CXCL8 and CXCL9) and TNF- $\alpha$.

\section{Methods}

\section{Subjects}

This study included patients with CL $(\mathrm{n}=22), \mathrm{ML}(\mathrm{n}=$ $11)$ or $\mathrm{SC}(\mathrm{n}=18)$ and HS controls $(\mathrm{n}=14)$. All patients were seen at Corte de Pedra Health Post, located in the southeast region of the State of Bahia, Brazil, which is well known for its high rate of L. braziliensis transmission. Some experiments did not include samples from every patient because some of the experiments in this study required a larger number of cells than could be obtained from the patients. The diagnostic criteria were a clinical picture characteristic of CL or ML, parasite isolation or a positive delayed-type hypersensitivity (DTH) response to leishmania antigen, and histological features of CL or ML. Household contacts of ATL patients without past or current history of leishmaniasis with a positive DTH test and/ or IFN- $\gamma$ production in cultures stimulated with SLA were considered as having subclinical infection. The physical examination of these individuals did not show a typical scar of CL. Immunological analyses were performed prior to therapy for all patients. Healthy subjects were composed of students at the Federal University of Bahia.

This study was approved by the Ethical Committee of the Federal University of Bahia. Informed consent was obtained from all enrolled subjects.

\section{Parasites}

A L. braziliensis (MHOM/BR/2003/LTCP15344) isolate obtained from a skin lesion on a CL patient was initially cultivated in biphasic medium (NNN). Following isolation, the parasites were cryopreserved in frozen nitrogen. The parasites selected for this study had not been previously passaged in liquid culture medium. After selection, the parasites were expanded in complete Schneider's medium. The isolate was identified as L. braziliensis by multilocus enzyme electrophoresis [17].

\section{Soluble leishmania antigen (SLA)}

The leishmania lysate (crude antigen) was prepared from a L. braziliensis strain (MHOM/BR/2001) as previously described [18].

\section{Cell separation and macrophage culture}

Peripheral blood mononuclear cells (PBMCs) were isolated from heparinized blood using Ficoll Hypaque (LSM; Organon, Durham, NC). Monocytes were separated by adherence. After 6 days of culture in complete RPMI 1640 (10\% heat inactivated human AB serum, $100 \mathrm{U}$ penicillin/ml, $100 \mu \mathrm{g}$ streptomycin/ml) (GIBCO BRL, Grand Island, NY, USA), the adherent cells displayed characteristics of monocytes-derived macrophages.

More than $99 \%$ of the cells in culture were identified as macrophages by microscopic observation. To assess purity of macrophages, adherent cells were removed by harvesting and analyzed by flow cytometry. Macrophages were gated according to their characteristic forward- and side-scatter. Purity was assessed by analysis using the following conjugated mouse anti-human mabs: CD14-PECy5 (macrophages), CD3-PE (T cells), CD19- FITC (B cells), and were confirmed to be $\mathrm{CD} 14^{+}, \mathrm{CD}^{-}, \mathrm{CD} 19^{-}$. The $\mathrm{T}$ cell influence on the system was considered to be absent because the adherent cell population consisted of less than $1 \% \mathrm{CD}^{+} \mathrm{T}$ cells (data not shown). We also evaluated the production of IFN- $\gamma$ in supernatants of infected macrophages by ELISA and observed that the IFN- $\gamma$ levels were very low or undetectable.

\section{Macrophage infection by L. braziliensis and evaluation of chemokines and TNF- $\alpha$ production}

PBMC-derived macrophages from HS and from SC, CL and ML patients were infected with $L$. braziliensis 
stationary phase promastigotes at a 2:1 ratio. Uninfected macrophages and LPS-stimulated macrophages (100 ng/ $\mathrm{ml}$ ) were used as controls. Infected macrophages were incubated at $37^{\circ} \mathrm{C}$ in $5 \% \mathrm{CO}_{2}$ for $2 \mathrm{~h}$. After incubation, the remaining extracellular parasites were removed by gentle washing. Cells were stained with Giemsa stain after 2, 48 and $96 \mathrm{~h}$ of infection, and the infection levels were determined by counting the percentage of infected cells and the number of amastigotes per 100 macrophages. This analysis was performed by two independent observers who were blinded to the experimental conditions. After each timepoint, supernatants were harvested and stored at $-70^{\circ} \mathrm{C}$ for analysis of chemokines, TNF- $\alpha$ $\mathrm{NO}$ and $\mathrm{O}_{2}{ }^{-}$production.

Determination of Nitric Oxide and superoxide production Nitrite $\left(\mathrm{NO}_{2}{ }^{-}\right)$accumulation in the cell culture supernatants was used as an indicator of NO production and was determined by a standard Griess reaction [19]. Superoxide production $\left(\mathrm{O}_{2}^{-}\right)$was determined by adding hydroxylamine $(0.5 \mathrm{mM})$ to cultures of infected macrophages $[20,21]$. Hydroxylamine converts superoxide into nitrite, which can be quantified by performing the Griess reaction, as described above. Background levels of nitrite generated by the release of $\mathrm{NO}$ were determined in parallel, without the addition of hydroxylamine.

\section{Determination of chemokines and TNF- $\alpha$ production}

The cell culture supernatants from HS, SC, CL and ML patients were assayed for CCL2, CCL3, CXCL8, CXCL9 and TNF- $\alpha$ after 2, 48 and $96 \mathrm{~h}$ of infection by ELISA (BD Pharmingen and R\&D Systems, Minneapolis, MN). Purified cytokines were used to derive a standard curve. The sensitivity of the cytokine assays was $15.6 \mathrm{pg} / \mathrm{ml}$ (CXCL8), $15.6 \mathrm{pg} / \mathrm{ml}$ (CXCL9), $7.8 \mathrm{pg} / \mathrm{ml}$ (CCL2), $7.8 \mathrm{pg} / \mathrm{ml}$ (CCL3) and $15.6 \mathrm{pg} / \mathrm{ml}(\mathrm{TNF}-\alpha)$.

\section{Statistical analysis}

Kruskal-Wallis with Dunn's post-test was used to analyze the results from the macrophage infection experiments and to compare the levels of chemokines TNF- $\alpha, \mathrm{NO}$ and $\mathrm{O}_{2}{ }^{-}$produced by macrophages. The cut-off for statistical significance was set at $p<0.05$. Statistical analysis was performed using Grand Prism 3.0 (GraphPad software, San Diego, CA, USA)

\section{Results}

\section{Susceptibility of human macrophages to L. braziliensis} infection

To determine the susceptibility of macrophages to $L$. braziliensis, as well as their ability to kill this parasite, adherent cells from the 4 different groups of subjects (HS, SC, $\mathrm{CL}$ and $\mathrm{ML}$ ) were infected with $L$. braziliensis stationary phase promastigotes. The percentage of infected cells and the number of intracellular amastigotes/100 macrophages were similar in the groups at $2 \mathrm{~h}$ after infection (Figures $1 \mathrm{~A}$ and $1 \mathrm{~B}$ ). After $48 \mathrm{~h}, \mathrm{SC}$ macrophages had a lower proportion of infected cells and a lower number of amastigotes per 100 cells compared to $\mathrm{HS}, \mathrm{CL}$ and $\mathrm{ML}$ macrophages $(\mathrm{SC} \times \mathrm{HS}, p<0.001$; $\mathrm{SC} \times \mathrm{CL}, p<0.01$; $\mathrm{SC}$ $\times$ ML, $p<0.001)$. After $96 \mathrm{~h}$ of infection, the percentage of infected macrophages and number of amastigotes per 100 cells declined in all four groups. However, both values were significantly lower in the SC patients compared to HS and ML patients $p<0.001$ (Figures $1 \mathrm{~A}$ and 1B).

\section{L. braziliensis killing is not associated with $\mathrm{NO}$ and superoxide production}

L. braziliensis infection increased NO production and the NO levels tended to be higher at $96 \mathrm{~h}$ of infection (Figure 2A). This trend coincided with a significant decrease in the intracellular parasite number in the SC group. There was no statistical difference in NO production among the groups (Figure 2A). Superoxide production by human infected macrophages increased after $96 \mathrm{~h}$ of infection but there was no statistical difference in superoxide production between the groups analyzed after 48 and 96 h (Figure 2B).

\section{Chemokines production by macrophages after infection with L. braziliensis}

Macrophages from all clinical forms produced low and similar levels of chemokines at $2 \mathrm{~h}$ after infection (data not shown). Figures 3 and 4 show the CCL2, CCL3, CXCL8 and CXCL9 levels in the supernatants of L. braziliensis-infected macrophages at $48 \mathrm{~h}$ of culture. CCL2 production was quite variable. CL macrophages (median $4660 \mathrm{pg} / \mathrm{ml}$, range 0-31618 pg/ml) and ML macrophages $(6080 \mathrm{pg} / \mathrm{ml}$, range 3600-25270) produced more CCL2 than SC cultures (median 447 range from 0 to 4700; $p<$ 0.05) (Figure 3A). CXCL8 levels in CL (median $4790 \mathrm{pg} /$ $\mathrm{ml}, 960-16250 \mathrm{pg} / \mathrm{ml}$ ) and ML $(5360 \mathrm{pg} / \mathrm{ml}, 336-32100$ $\mathrm{pg} / \mathrm{ml}$ ) cultures were also higher than in SC individuals ( $570 \mathrm{pg} / \mathrm{ml}, 136-4980 \mathrm{pg} / \mathrm{ml} ; p<0.05$ ) (Figure 3B). CCL3 was detected in all groups and did not show significant differences among groups (data not shown). The levels of CXCL9 were significantly higher in CL $(1510 \mathrm{pg} / \mathrm{ml}, 0$ $17205 \mathrm{pg} / \mathrm{ml}$ ) and ML patients $(16396 \mathrm{pg} / \mathrm{ml}, 4324-25080$ $\mathrm{pg} / \mathrm{ml}$ ) compared with HS (66 pg/ml, 0-390 pg/ml; $p<$ 0.001). SC patients produced less CXCL9 $(265 \mathrm{pg} / \mathrm{ml}, 47-$ 2905) than either the ML and CL patients $(p<0.001 ; p<$ 0.05 ) (Figure 4). At $96 \mathrm{~h}$ of culture the levels of chemokines were still high (data not shown) and similar to the levels at $48 \mathrm{~h}$. No differences in LPS-induced CCL2, CXL8 and CXCL9 production were observed between groups $(p>0.05)$ (data not shown). 

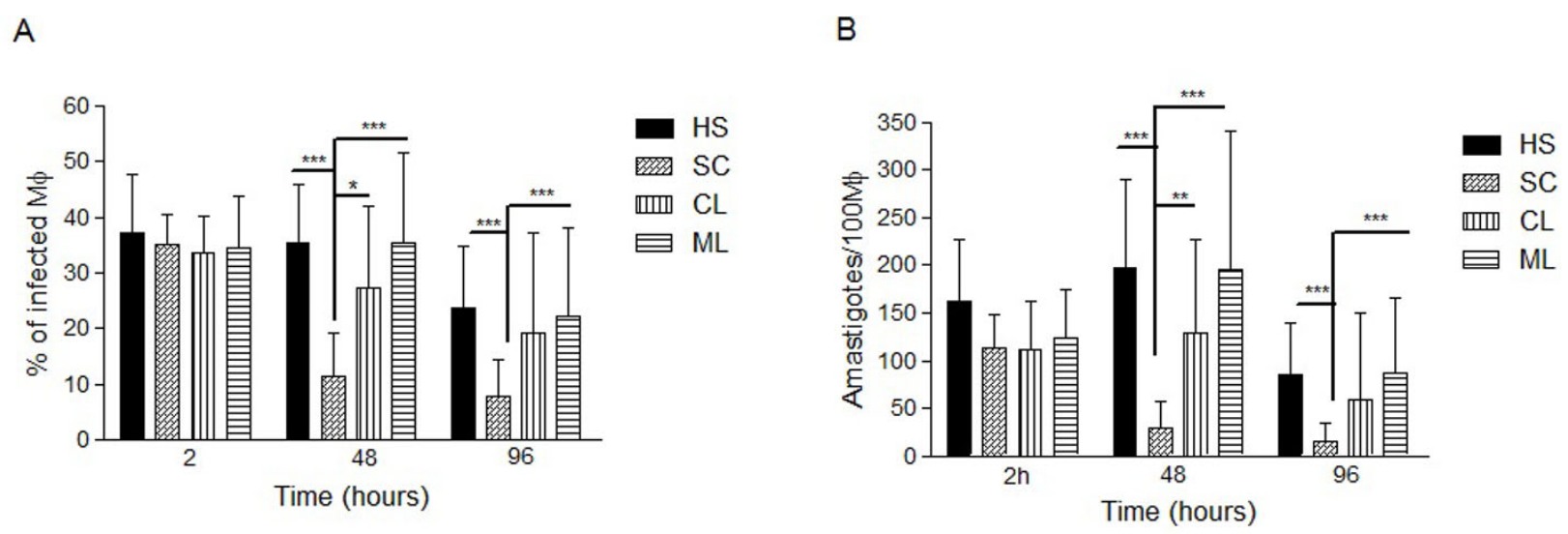

Figure 1 Phagocytosis and killing of L. braziliensis by macrophages from different forms of L. braziliensis infection. Human monocyte derived-macrophages from HS $(n=12), S C(n=12), C L(n=10)$ and ML $(n=11)$ were infected with L. braziliensis in the stationary phase of growth at a 2:1 ratio. The percentage of infected macrophages (A) and the parasite burden (B) were evaluated at 2, 48 and $96 \mathrm{~h}$ after infection. Data represent the mean $\pm \mathrm{SD}$. Statistical analysis was performed using the Kruskal-Wallis test. ( $\left.{ }^{*} p<0.05,{ }^{* *} p<0.01,{ }^{* * *} p<0.001\right)$.

Production of TNF- $\alpha$ by macrophages after infection with L. braziliensis

Macrophages from CL, ML, SC and HS patients produced low and similar levels of TNF- $\alpha$ at $2 \mathrm{~h}$ after infection (data not shown). At $48 \mathrm{~h}$ secreted TNF- $\alpha$ in disease-specific patterns (Figure 5). Leishmania-infected macrophages from $\mathrm{ML}$ and $\mathrm{CL}$ patients secreted more TNF- $\alpha$ (64 pg/ml-ranging 1-341 pg/ml and $52 \mathrm{pg} / \mathrm{ml}$, ranging $0-170 \mathrm{pg} / \mathrm{ml}$, respectively) than macrophages from HS $(0 \mathrm{pg} / \mathrm{ml}$, ranging $0-74 \mathrm{pg} / \mathrm{ml}, p<0.01$ and $p<$ $0.05)$. SC macrophages secreted less TNF- $\alpha(1.05 \mathrm{pg} / \mathrm{ml}$ and $0-6.2 \mathrm{pg} / \mathrm{ml}$ respectively) than cells from $\mathrm{ML}$ and $\mathrm{CL}$ patients $p<0.01$ and $p<0.05$ (Figure 5). At $96 \mathrm{~h}$ of culture the levels of TNF- $\alpha$ still were still high (data not shown) and similar to levels at $48 \mathrm{~h}$. No difference $(p>$ $0.05)$ in LPS-induced TNF- $\alpha$ production was observed between groups (data not shown).

\section{Discussion}

Macrophages are important for Leishmania infection because they can host the parasite for a long period of time, act as antigen presenting cells and secrete molecules that induce inflammatory response and may kill Leishmania. In this study we compared the ability of L. braziliensis to infect and survive in macrophages from individuals with different clinical forms of L. braziliensis infection. Furthermore, we measured molecules secreted by these cells. Our data clearly show that individuals with SC
A

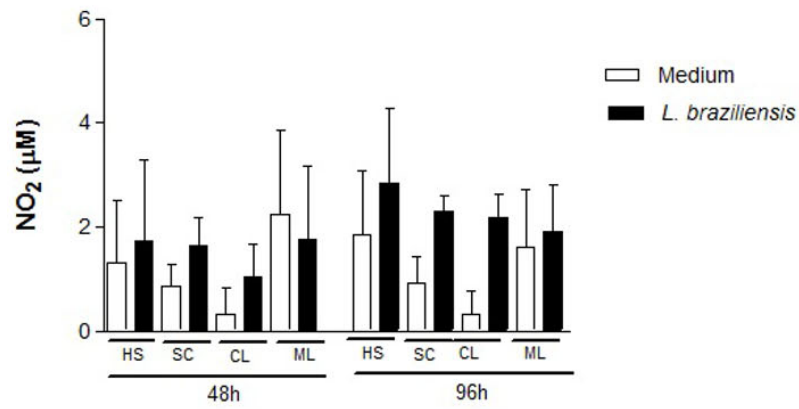

B

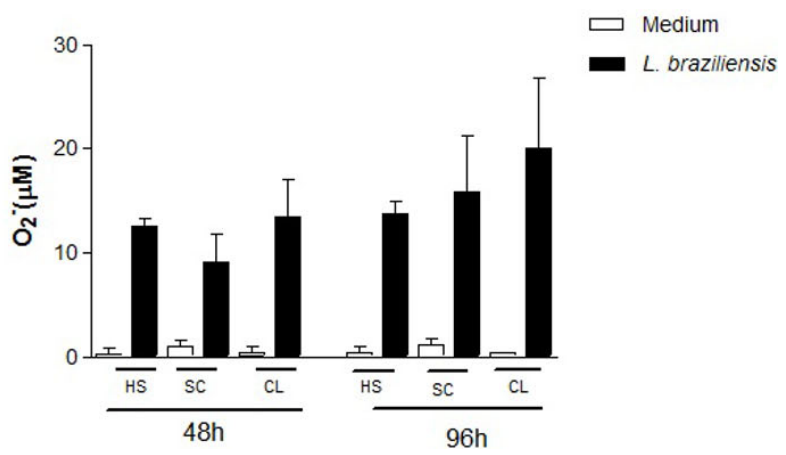

Figure 2 Nitric Oxide (NO) and superoxide production by macrophages after infection with L. braziliensis. Six-day monocyte derivedmacrophages from HS $(n=6), S C(n=6), C L(n=6)$ and $M L(n=05)$ groups were infected or left uninfected with L. braziliensis at a 2:1 ratio. After 48 and 96 h, the supernatants were collected for detection of NO (A) and superoxide (B) using the Griess reaction. The data are expressed as the mean \pm SD. Statistical analysis was performed using the Kruskal-Wallis test. $(p>0.05)$. 


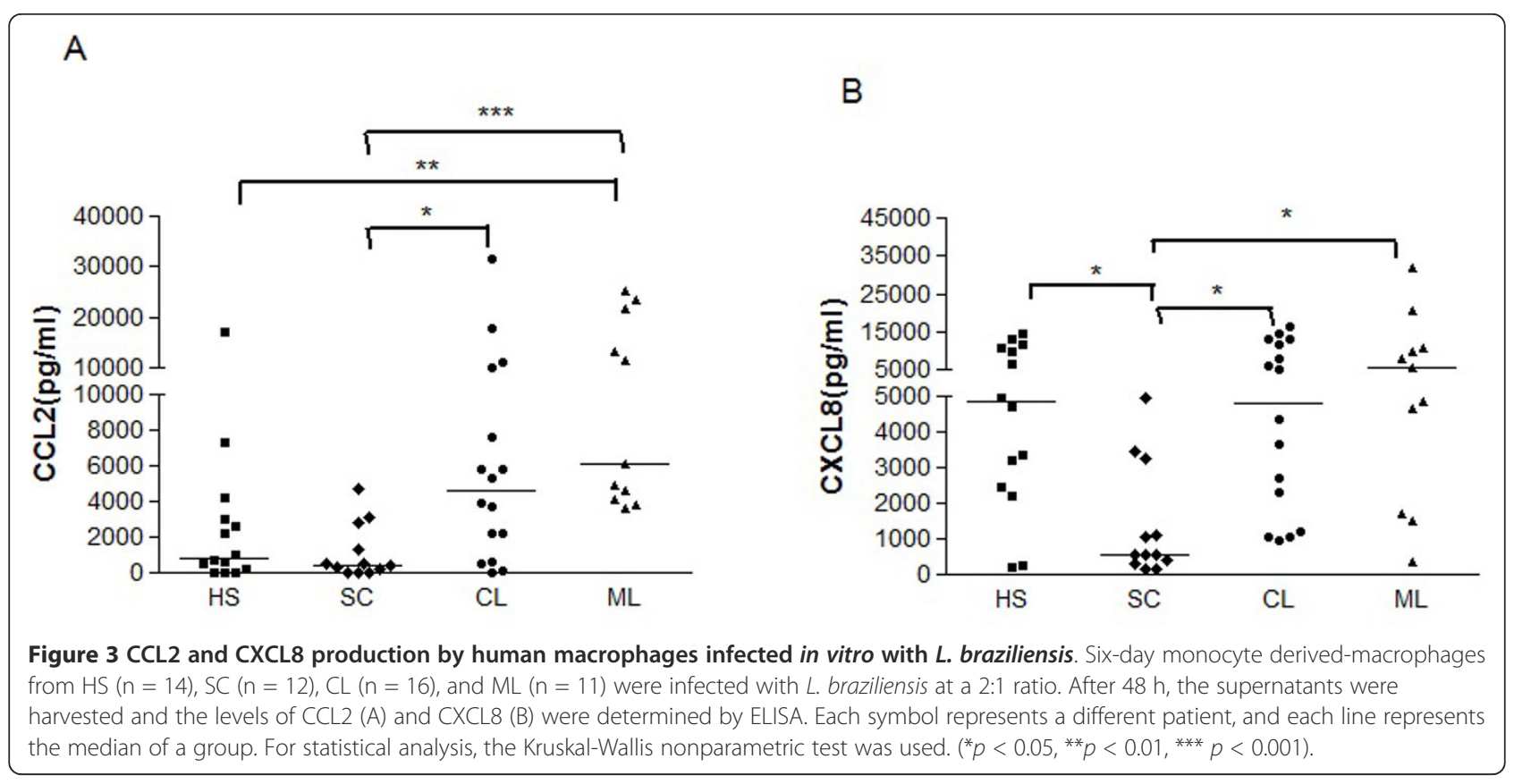

L. braziliensis infection can control parasite growth in the absence of $\mathrm{T}$ cells or $\mathrm{T}$ cell products through the ability of their macrophages to kill Leishmania. Alternatively, macrophages from CL and ML patients allow Leishmania survival and produce high amounts of pro-inflammatory chemokines that attract neutrophils, monocytes and

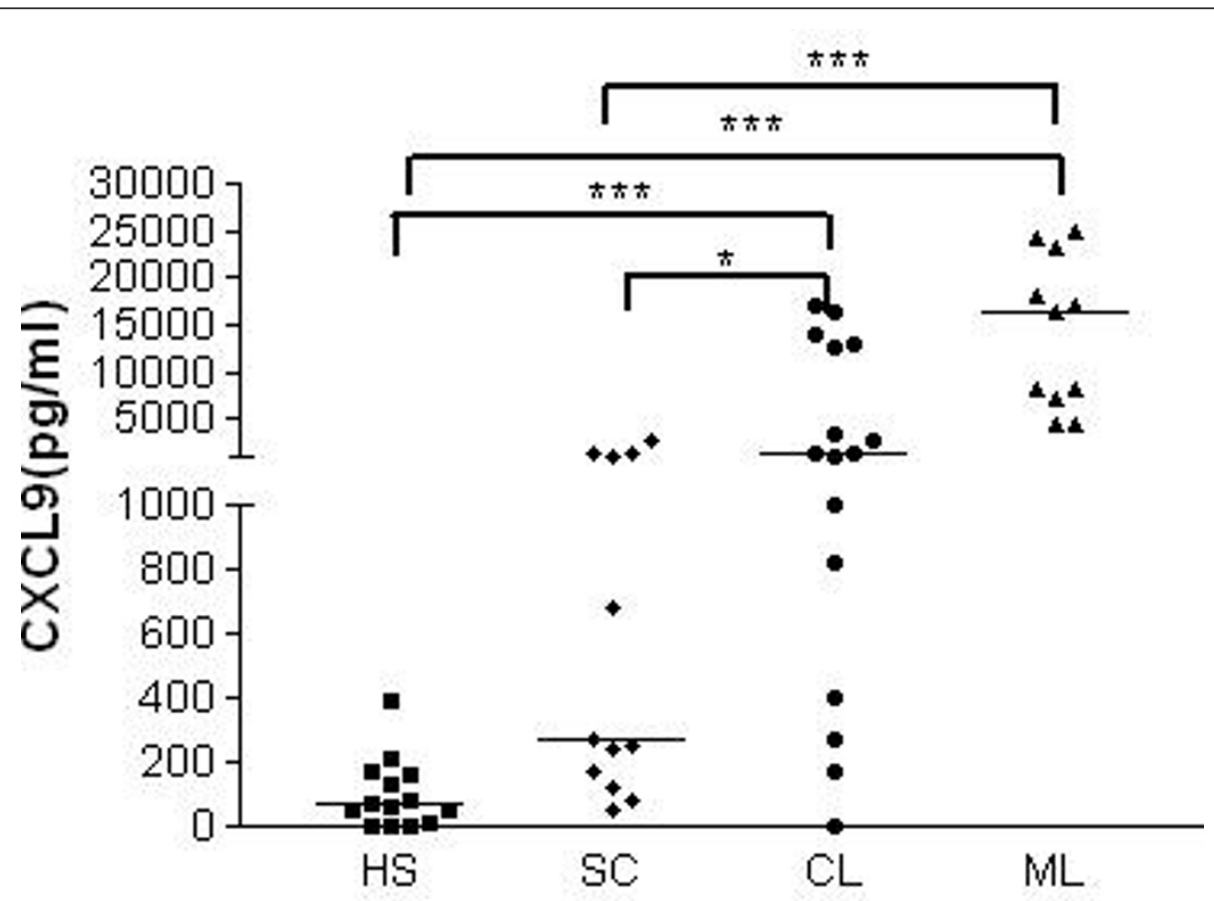

Figure 4 CXCL9 production by infected human macrophages cultured in vitro in the presence of L. braziliensis. Six-day monocyte derived-macrophages from HS $(n=14), S C(n=12), C L(n=16)$, and ML $(n=11)$ were infected in vitro with L. braziliensis at a 2:1 ratio. After 48 $h$, the supernatants were harvested and the levels of CXCL9 were determined by ELISA. Each symbol represents a different patient, and each line represents the median of a group. For statistical analysis, the Kruskal-Wallis test was used. $\left.{ }^{*} p<0.05 ;{ }^{* * *} p<0.001\right)$. 


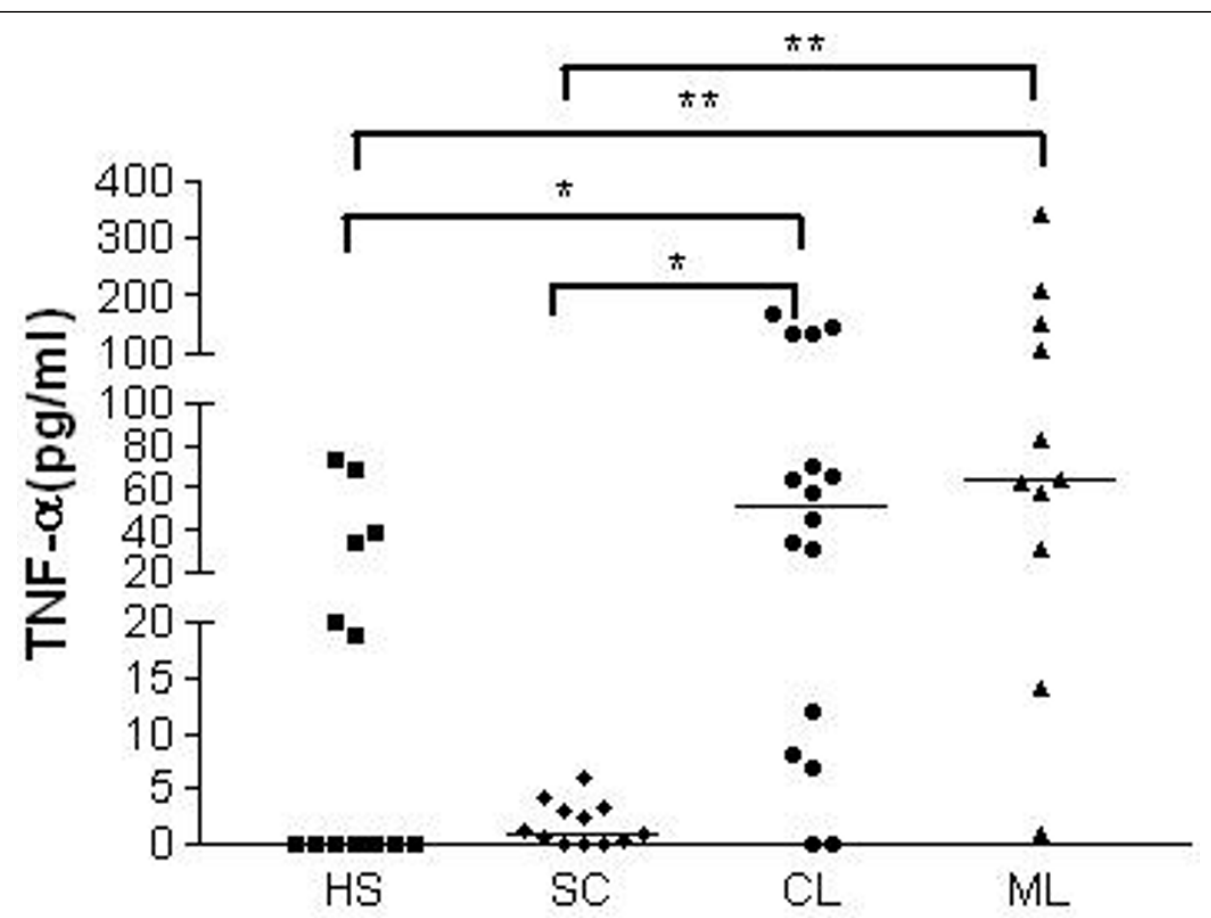

Figure 5 TNF- $\alpha$ production by human macrophages infected in vitro with L. braziliensis. Six-day monocyte derived-macrophages from HS $(n=14), S C(n=12), C L(n=16)$, and ML $(n=11)$ were cultured in the presence of L. braziliensis at a 2:1 ratio. After 48 h, the supernatants were harvested and the levels of TNF- $\alpha$ were determined by ELISA. Each symbol represents a different patient, and each line represents the median of a group. For statistical analysis, the Kruskal-Wallis nonparametric test was used. $\left({ }^{*} p<0.05 ;{ }^{* *} p<0.01\right)$.

activated $\mathrm{T}$ cells that induce an inflammatory reaction and contribute to the pathology associated with the L. braziliensis infection.

Analyzing macrophage function in individuals with different clinical forms of L. braziliensis fills a gap in our understanding of the pathogenesis of leishmaniasis. The Th1-type immune response controls parasite multiplication and dissemination in CL and ML, but it does not eradicate Leishmania infection [22]. Moreover, this exaggerated and non-modulated type- 1 immune response observed in CL and ML is associated with the production of pro-inflammatory cytokines and tissue damage [7]. In contrast, individuals with SC L. braziliensis infection control parasite growth and do not develop the disease, despite producing only low levels of IFN- $\gamma$, the main cytokine that activates macrophages to kill Leishmania. Therefore, it is likely that in SC individuals the innate immune response plays an important role in the control of parasite growth. Macrophages from sub-clinically infected individuals have been shown to be susceptible to infection by L. panamensis than macrophages from patients with recurrent leishmaniasis [23]. In the present study, all groups of macrophages infected with L. braziliensis had equal numbers of amastigotes at two hours after infection. We conclude that penetration of Leishmania into macrophages is independent of the clinical group from which the macrophage samples were obtained. However, while the percentage of infected cells and number of amastigotes decreased in macrophages from individuals with SC infection, the parasite load in $\mathrm{CL}$ and ML remained high, indicating that cells from SC patients have a greater ability to kill parasites than cells from CL and ML patients. The mechanisms used by human macrophages to kill Leishmania are not yet well established. NO plays an important role in controlling established murine leishmaniasis infection [24]. A recent study showed that NO production remained unchanged in a co-culture of human neutrophils with macrophages infected with L. braziliensis [25]. Our results show that macrophages infected with $L$. braziliensis produced NO and $\mathrm{O}_{2}{ }^{-}$, although no differences were observed among the different groups, suggesting that macrophage-derived oxidants are not critical in controlling the macrophage infection of Leishmaniasis patients by L. braziliensis. Analyzing different isolates of Leishmania that originated from patients with CL from an endemic area of L. braziliensis transmission identified some isolates that were resistant to death by NO, which positively correlated with lesion size [26]. These data suggest that NO production is not the main mechanism used by macrophages to kill Leishmania. The interaction between $\mathrm{NO}$ and $\mathrm{O}_{2}{ }^{-}$ leads to the formation of peroxynitrite (ONOO-ROS), 
which has been shown to have a greater toxic effect in vitro in amastigotes when compared to $\mathrm{NO}[27,28]$. Further studies are warranted to evaluate the role of peroxynitrite in the killing of L. braziliensis.

Chemokines participate in the inflammatory reaction during Leishmania infection. While CCL3 was produced in similar amounts by macrophages from all four groups, the production of CCL2, CXCL8 and CXCL9 after $L$. braziliensis infection was significantly higher in macrophages from CL and ML patients than in those from SC patients. CXCL8 attracts neutrophils to the inflammatory site where they are phagocytized by macrophages. Depending on whether the neutrophils are apoptotic or necrotic, macrophages can control or allow parasite load growth [25,29]. Exogenous addition of CCL2 is a highly specific chemotactic factor for macrophages and T-lymphocytes that enhances $L$. infantum killing by human macrophages [12]. This chemokine showed increased expression in CL lesions compared with control biopsy samples [30]. The expression of CCL2 and CXCL9 was higher in CL tissue cells than in diffuse cutaneous leishmaniasis tissue [11]. CXCL9, previously called a monokine, is induced by IFN- $\gamma$ (MIG) and has the ability to attract $\mathrm{T}$ cells to the site of inflammation. These observations suggest that different chemokines may influence the parasite multiplication, the inflammation and the clinical manifestations of leishmaniasis [12,30]. However, CL and ML macrophages secreted higher levels of CCL2 and CXCL9 but did not kill Leishmania, making it more likely that these chemokines are involved more in the inflammatory reaction and tissue damage in CL and ML patients than in protecting them against $L$. braziliensis infection. CXCL9 is secreted in high levels in chronic inflammatory and auto-immune diseases, such as human $\mathrm{T}$ cell lymphotropic virus infection and multiple sclerosis. In both cases, CXCL9 is associated with inflammation and the disease pathology [31,32].

TNF- $\alpha$ plays an important role in protecting humans and mice against leishmaniasis [33,34]. However, TNF- $\alpha$ can also mediate the ATL pathology [35-39] Here, we show that macrophages from CL and ML patients produce TNF- $\alpha$ after exposure to L. braziliensis infection. Macrophages from CL and ML kill fewer parasites than macrophages from $\mathrm{SC}$, which implies that these cells contribute to the pathology of CL and ML by producing pro-inflammatory cytokines.

The explanation for why CL and ML groups produce higher levels of chemokines and TNF- $\alpha$ is now under evaluation. For instance genetic factors such as polymorphisms in TLR receptors may partly explain this difference. Alternatively, parasite factors may also stimulate the production of chemokines and TNF- $\alpha$. Recent studies have shown a RNA virus that actives TLR-3 in some Leishmania species associated with mucosal disease [40]. This study builds on previous observations that individuals with $\mathrm{SC}$ infection can control the $L$. braziliensis parasite despite a poor type-1 immune response [10], while the exaggerated inflammatory response and $\mathrm{T}$ cell activation observed in CL and ML contribute to the development of ulcers [35,41]. In this research, we show that macrophages play a pivotal role in the pathogenesis of tegumentary leishmaniasis by decreasing the parasite load in subjects with subclinical $L$. braziliensis infection, even in the absence of $\mathrm{T}$ cells and inducing pathology in CL and ML patients, by increasing pro-inflammatory chemokines and cytokines.

\section{Conclusions}

This study shows that macrophages may play a pivotal role in the pathogenesis of human leishmaniasis and that their function may determine the clinical outcome of $L$. braziliensis infection. In SC disease, macrophages efficiently kill parasites and control parasite growth without tissue damage, while macrophages from CL and ML patients allow parasite survival and secrete inflammatory molecules that activate and recruit other cells, leading to pathology. The mechanisms for these findings are not completely understood but provide a fascinating subject for investigation.

\section{Acknowledgements}

We thank Elbe Silva, Maria Lúcia Reis and Cristiano S. Franco for secretarial assistance. This study was supported by $\mathrm{NIH}$ grant Al088650, NIH grant Al30639 and the Brazilian National Research Council (CNPq), Universal 472198/2009-2. EMC is a senior investigator of the CNPq and OB is an investigator of the CNPq.

\section{Author details}

'Serviço de Imunologia, Complexo Hospitalar Universitário Professor Edgard Santos, Universidade Federal da Bahia, Salvador, Bahia, Brazil. ${ }^{2}$ Instituto Nacional de Ciência e Tecnologia de Doenças Tropicais- INCT-DT(CNPq/ MCT), Salvador, Bahia, Brazil. ${ }^{3}$ Complexo Hospitalar Universitário Prof. Edgard Santos, Serviço de Imunologia, 50 andar, Rua João das Botas, s/n, Canela, 40110-160 Salvador, BA, Brazil.

\section{Authors' contributions}

$A G, C V, E M C$ and $O B$ participated equally in the study design. AG, CV, LPC and TL participated in the human macrophages infection and NO detection experiments. AG, CV and $C B$ participated in detecting the levels of chemokines and TNF- $a$. EMC and $\mathrm{OB}$ are the principal investigators of this work and followed the work from the beginning to the end and also participated in the writing of the manuscript. All authors read and approved the final manuscript.

\section{Competing interests}

The authors declare that they have no competing interests.

Received: 14 October 2011 Accepted: 29 March 2012

Published: 29 March 2012

\section{References}

1. Bittencourt AL, Barral A: Evaluation of the histopathological classifications of American cutaneous and mucocutaneous leishmaniasis. Mem Inst Oswaldo Cruz 1991, 86(1):51-56. 
2. Marsden PD, Jones TC: Clinical manifestations, diagnosis and treatment of leishmaniasis Amsterdam: Elsevier Science Publisher; 1985.

3. Ben Salah A, Louzir H, Chlif S, Mokni M, Zaatour A, Raouene M, Ismail RB, Dellagi K: The predictive validity of naturally acquired delayed-type hypersensitivity to leishmanin in resistance to Leishmania majorassociated cutaneous leishmaniasis. J Infect Dis 2005, 192(11):1981-1987.

4. Bittar RC, Nogueira RS, Vieira-Goncalves R, Pinho-Ribeiro V, Mattos MS, Oliveira-Neto MP, Coutinho SG, Da-Cruz AM: T-cell responses associated with resistance to Leishmania infection in individuals from endemic areas for Leishmania (Viannia) braziliensis. Mem Inst Oswaldo Cruz 2007, 102(5):625-630.

5. Follador I, Araujo C, Orge G, Cheng LH, de Carvalho LP, Bacellar O, Almeida RP, Carvalho EM: Immune responses to an inactive vaccine against American cutaneous leishmaniasis together with granulocytemacrophage colony-stimulating factor. Vaccine 2002, 20(9-10):1365-1368.

6. Trujillo CM, Robledo SM, Franco JL, Velez ID, Erb KJ, Patino PJ: Endemically exposed asymptomatic individuals show no increase in the specific Leishmania (Viannia) panamensis-Th1 immune response in comparison to patients with localized cutaneous leishmaniasis. Parasite Immunol 2002, 24(9-10):455-462.

7. Bacellar O, Lessa H, Schriefer A, Machado P, Ribeiro De Jesus A, Dutra WO Gollob K, Carvalho EM: Up-regulation of Th1-type responses in mucosal leishmaniasis patients. Infect Immun 2002, 70(12):6734-6740.

8. Carvalho LP, Passos S, Bacellar O, Lessa M, Almeida RP, Magalhaes A, Dutra WO, Gollob KJ, Machado P, de Jesus AR: Differential immune regulation of activated T cells between cutaneous and mucosal leishmaniasis as a model for pathogenesis. Parasite Immunol 2007, 29(5):251-258.

9. Carvalho EM, Johnson WD, Barreto E, Marsden PD, Costa JL, Reed S, Rocha H: Cell mediated immunity in American cutaneous and mucosal leishmaniasis. J Immunol 1985, 135(6):4144-4148.

10. Follador I, Araujo C, Bacellar O, Araujo CB, Carvalho LP, Almeida RP, Carvalho EM: Epidemiologic and immunologic findings for the subclinical form of Leishmania braziliensis infection. Clin Infect Dis 2002, 34(11): E54-E58.

11. Ritter U, Korner $\mathrm{H}$ : Divergent expression of inflammatory dermal chemokines in cutaneous leishmaniasis. Parasite Immunol 2002, 24(6):295-301.

12. Brandonisio O, Panaro MA, Fumarola I, Sisto M, Leogrande D, Acquafredda A, Spinelli R, Mitolo V: Macrophage chemotactic protein-1 and macrophage inflammatory protein-1 alpha induce nitric oxide release and enhance parasite killing in Leishmania infantum-infected human macrophages. Clin Exp Med 2002, 2(3):125-129.

13. Faria DR, Gollob KJ, Barbosa J Jr, Schriefer A, Machado PR, Lessa H, Carvalho LP, Romano-Silva MA, de Jesus AR, Carvalho EM, et al: Decreased in situ expression of interleukin-10 receptor is correlated with the exacerbated inflammatory and cytotoxic responses observed in mucosal leishmaniasis. Infect Immun 2005, 73(12):7853-7859.

14. Assreuy J, Cunha FQ, Epperlein M, Noronha-Dutra A, O'Donnell CA, Liew FY, Moncada S: Production of nitric oxide and superoxide by activated macrophages and killing of Leishmania major. Eur J Immunol 1994, 24(3):672-676

15. Evans TG, Thai L, Granger DL, Hibbs JB Jr: Effect of in vivo inhibition of nitric oxide production in murine leishmaniasis. J Immunol 1993, 151(2):907-915.

16. Murray HW, Teitelbaum RF: L-arginine-dependent reactive nitrogen intermediates and the antimicrobial effect of activated human mononuclear phagocytes. J Infect Dis 1992, 165(3):513-517.

17. Cupolillo E, Grimaldi G Jr, Momen H: A general classification of New World Leishmania using numerical zymotaxonomy. Am J Trop Med Hyg 1994, 50(3):296-311.

18. Reed SG, Badaro R, Masur H, Carvalho EM, Lorenco R, Lisboa A, Teixeira R, Johnson WD Jr, Jones TC: Selection of a skin test antigen for American visceral leishmaniasis. Am J Trop Med Hyg 1986, 35(1):79-85.

19. Ding AH, Nathan CF: The measurement of cytochrome b559 in polymorphonuclear leukocytes and macrophages in the presence of hemoglobin or mitochondrial cytochromes. Anal Biochem 1988, 175(1):22-29.

20. Elstner $E F$, Heupel A: Inhibition of nitrite formation from hydroxylammoniumchloride: a simple assay for superoxide dismutase. Anal Biochem 1976, 70(2):616-620.
21. Khouri R, Bafica A, Silva Mda P, Noronha A, Kolb JP, Wietzerbin J, Barral A, Barral-Netto M, Van Weyenbergh J: IFN-beta impairs superoxidedependent parasite killing in human macrophages: evidence for a deleterious role of SOD1 in cutaneous leishmaniasis. J Immunol 2009, 182(4):2525-2531.

22. Ribeiro-de-Jesus A, Almeida RP, Lessa H, Bacellar O, Carvalho EM: Cytokine profile and pathology in human leishmaniasis. Braz J Med Biol Res 1998, 31(1):143-148.

23. Bosque F, Saravia NG, Valderrama L, Milon G: Distinct innate and acquired immune responses to Leishmania in putative susceptible and resistant human populations endemically exposed to L. (Viannia) panamensis infection. Scand J Immunol 2000, 51(5):533-541.

24. Liew FY, Cox FE: Nonspecific defence mechanism: the role of nitric oxide. Immunol Today 1991, 12(3):A17-A21.

25. Novais FO, Santiago RC, Bafica A, Khouri R, Afonso L, Borges VM, Brodskyn C, Barral-Netto M, Barral A, de Oliveira Cl: Neutrophils and macrophages cooperate in host resistance against Leishmania braziliensis infection. J Immunol 2009, 183(12):8088-8098.

26. Giudice A, Camada I, Leopoldo PT, Pereira JM, Riley LW, Wilson ME, Ho JL, de Jesus AR, Carvalho EM, Almeida RP: Resistance of Leishmania (Leishmania) amazonensis and Leishmania (Viannia) braziliensis to nitric oxide correlates with disease severity in Tegumentary Leishmaniasis. BMC Infect Dis 2007, 7:7.

27. Linares E, Augusto O, Barao SC, Giorgio S: Leishmania amazonensis infection does not inhibit systemic nitric oxide levels elicited by lipopolysaccharide in vivo. J Parasitol 2000, 86(1):78-82.

28. Van Assche T, Deschacht M, da Luz RA, Maes L, Cos P: Leishmaniamacrophage interactions: insights into the redox biology. Free Radic Biol Med 2011, 51(2):337-351.

29. Afonso L, Borges VM, Cruz H, Ribeiro-Gomes FL, DosReis GA, Dutra AN, Clarencio J, de Oliveira Cl, Barral A, Barral-Netto M, et al: Interactions with apoptotic but not with necrotic neutrophils increase parasite burden in human macrophages infected with Leishmania amazonensis. J Leukoc Biol 2008, 84(2):389-396.

30. Campanelli AP, Brodskyn Cl, Boaventura V, Silva C, Roselino AM, Costa J, Saldanha AC, de Freitas LA, de Oliveira Cl, Barral-Netto M, et al: Chemokines and chemokine receptors coordinate the inflammatory immune response in human cutaneous leishmaniasis. Hum Immunol 2010, 71(12):1220-1227.

31. Guerreiro JB, Santos SB, Morgan DJ, Porto AF, Muniz AL, Ho JL, Teixeira AL $\mathrm{Jr}$, Teixeira MM, Carvalho EM: Levels of serum chemokines discriminate clinical myelopathy associated with human T lymphotropic virus type 1 (HTLV-1)/tropical spastic paraparesis (HAM/TSP) disease from HTLV-1 carrier state. Clin Exp Immunol 2006, 145(2):296-301.

32. Trebst C, Ransohoff RM: Investigating chemokines and chemokine receptors in patients with multiple sclerosis: opportunities and challenges. Arch Neurol 2001, 58(12):1975-1980.

33. Kanaly ST, Nashleanas M, Hondowicz B, Scott P: TNF receptor p55 is required for elimination of inflammatory cells following control of intracellular pathogens. J Immunol 1999, 163(7):3883-3889.

34. Pizzorni C, Secchi ME, Cutolo M: Leishmaniasis in rheumatoid arthritis. Reumatismo 2007, 59(3):235-239.

35. Antonelli LR, Dutra WO, Almeida RP, Bacellar O, Carvalho EM, Gollob KJ: Activated inflammatory T cells correlate with lesion size in human cutaneous leishmaniasis. Immunol Lett 2005, 101(2):226-230.

36. Da-Cruz AM, de Oliveira MP, De Luca PM, Mendonca SC, Coutinho SG Tumor necrosis factor-alpha in human american tegumentary leishmaniasis. Mem Inst Oswaldo Cruz 1996, 91(2):225-229.

37. Bafica A, Oliveira F, Freitas LA, Nascimento EG, Barral A: American cutaneous leishmaniasis unresponsive to antimonial drugs: successful treatment using combination of $\mathrm{N}$-methilglucamine antimoniate plus pentoxifylline. Int J Dermatol 2003, 42(3):203-207.

38. Machado PR, Lessa $H$, Lessa M, Guimaraes LH, Bang H, Ho JL, Carvalho EM: Oral pentoxifylline combined with pentavalent antimony: a randomized trial for mucosal leishmaniasis. Clin Infect Dis 2007, 44(6):788-793.

39. Sadeghian G, Nilforoushzadeh MA: Effect of combination therapy with systemic glucantime and pentoxifylline in the treatment of cutaneous leishmaniasis. Int J Dermatol 2006, 45(7):819-821.

40. Ives A, Ronet C, Prevel F, Ruzzante G, Fuertes-Marraco S, Schutz F, Zangger H, Revaz-Breton M, Lye LF, Hickerson SM, et al: Leishmania RNA 
virus controls the severity of mucocutaneous leishmaniasis. Science 2011, 331(6018):775-778

41. Pirmez C, Yamamura M, Uyemura K, Paes-Oliveira M, Conceicao-Silva F,

Modlin RL: Cytokine patterns in the pathogenesis of human

leishmaniasis. J Clin Invest 1993, 91(4):1390-1395.

Pre-publication history

The pre-publication history for this paper can be accessed here: http://www.biomedcentral.com/1471-2334/12/75/prepub

doi:10.1186/1471-2334-12-75

Cite this article as: Giudice et al:: Macrophages participate in host protection and the disease pathology associated with Leishmania braziliensis infection. BMC Infectious Diseases 2012 12:75.

Submit your next manuscript to BioMed Central and take full advantage of:

- Convenient online submission

- Thorough peer review

- No space constraints or color figure charges

- Immediate publication on acceptance

- Inclusion in PubMed, CAS, Scopus and Google Scholar

- Research which is freely available for redistribution

Submit your manuscript at www.biomedcentral.com/submit 